www.jmscr.igmpublication.org

Impact Factor (SJIF): 6.379

Index Copernicus Value: 71.58

ISSN (e)-2347-176x ISSN (p) 2455-0450

crossref DOI: https://dx.doi.org/10.18535/jmscr/v6i5.145

Journal Of Medical Science And Clinical Research

\title{
A Comparative Study between Efficacies of Povidone-Iodine (10\%) Solution Versus Alcohol Based Solution Hygienium as Skin Antiseptic
}

\section{Dr Mahendra Ekka ${ }^{1}$, Dr Dulal K.Soren ${ }^{2}$, Dr Malay Ku.Patel ${ }^{3}$, Dr Sheela Ekka ${ }^{4}$ Dr Sapan Ku.Jena ${ }^{5}$, Dr Saurbh Agrawal ${ }^{6}$}

${ }^{1,4}$ Assistant Professor, Dept of Anaesthesiology \& Critical care VIMSAR, Burla, Sambalpur, Odisha, India ${ }^{2,3}$ Associate Professor, Dept of Anaesthesiology \& Critical care VIMSAR, Burla, Sambalpur, Odisha, India ${ }^{5,6}$ Junior Resident, Dept of Anaesthesiology \& Critical care VIMSAR, Burla, Sambalpur, Odisha, India Corresponding Author

Dr Dulal K.Soren

Email: dulalsoren@gmail.com, Mobile no-9437254980

\begin{abstract}
Background and Objectives: Skin asepsis is a crucial measure for preventing infectious complications of central neuraxial block, i.e. meninigitis. The aim of this study was to comparative evaluatation of effectiveness of some conventional surgical antiseptic solutions and to identify the most effective one.

Material and Methods: Effectiveness of Hygenium was compared with Povidone-iodine (10\% Betadine) as skin antiseptic prior to administration of central neuraxial block. Two rounds of sampling were conducted, one before application of antiseptic solution and the second after skin preparation with antiseptic solution. Colonies were counted after 48 hours of aerobic incubation at $37^{\circ} \mathrm{C}$. All counts were conducted twice. Positive cultures were identified and their frequencies were compared. Data were summarized using descriptive statistical methods. Comparison of counts between groups was performed. Results: Out of 131 samples, positive culture in Hygenium as compared to Povidone-iodine (4.6\% v $6.2 \%)$ is statistically not significant showing equal efficacy. Staph. aureus, Staph epidermidis, Streptococcus, Diptheroids are most common organisms isolated in both the groups for testing the antiseptic efficacy.

Conclusions: Povidone-iodine and Hygenium are equally effective as antiseptic. Hygenium can preferably used in situations where lesser time is required for preparation of skin prior to administration of central neuraxial block and when patient positioning is difficult.

Keywords: Povidone-iodine, Alcohol-based Solutions, Hygienium, Skin asepsis,
\end{abstract}

\section{Introduction}

Skin asepsis is one of the major concern in central neuraxial block to prevent the most serious complication i.e, meningitis ${ }^{[1]}$. The incidence of infectious complications with epidural catheters is very low. However, when it occurs, it can have disastrous implications for patients ${ }^{[2]}$. The most appropriate and safe antiseptic solution for skin asepsis in central neuraxial block remains controversial till now. The ideal antiseptic agent should be effective against a wide range of microorganisms, exert a long term effect and 
should have minimum toxic effect on skin. There are conflicting reports regarding preferred agent for cutaneous antisepsis but among the commonly used solutions are $10 \%$ aqueous solution of Povidone-iodine, 2\% chlorhexidene in alcohol, isopropyl alcohol. Some studies shown that povidone iodine and chlorohexidine may cause chemical meningitis at a dose of as less as $0.1 \mathrm{ml}$ of solution into CSF. Isopropyl alcohol due to less drying time maintains asepsis, but does not have residual effect as needed in placing epidural catheter. The Hygenium contains isopropyl alcohol, 1-propanol and mecetronium ethylsulfate that provides skin asepsis and residual effect due to mecetronium ethylsulfate. Our primary aim therefore was to compare the efficacy of these agents for cutaneous antisepsis.

This study was done to compare the efficacy of povidone iodine with Hygenium as skin antiseptics in OT setting.

\section{Materials \& Methods;}

This observational study was undertaken in Ortho OT VIMSAR in time period from September 2017 to November 2017. Basing on previous study by Kadam $R$ et $a l^{[5]}$, the sample size calculated to be 61 in each group considering power of 80 and alfa error of $5 \%$. Considering drop outs in the study sample size was taken as 70 in each group. 140 patients posted for surgery under spinal anaesthesia were enrolled into this study. Four participants having local skin disease were excluded. There was also no absolute or relative contra indications to spinal anaesthesia. The patients were randomly allocated into two groups of 68 each i.e. Group P for povidone iodine and Group $\mathrm{H}$ for Hygenium. Out of these, 3 patients in group $\mathrm{P} \& 2$ patients in group $\mathrm{H}$ were discarded due to culture contamination. Hence total patients in Group P \& Group H were 65 \& 66 respectively as shown in the flow diagram below.

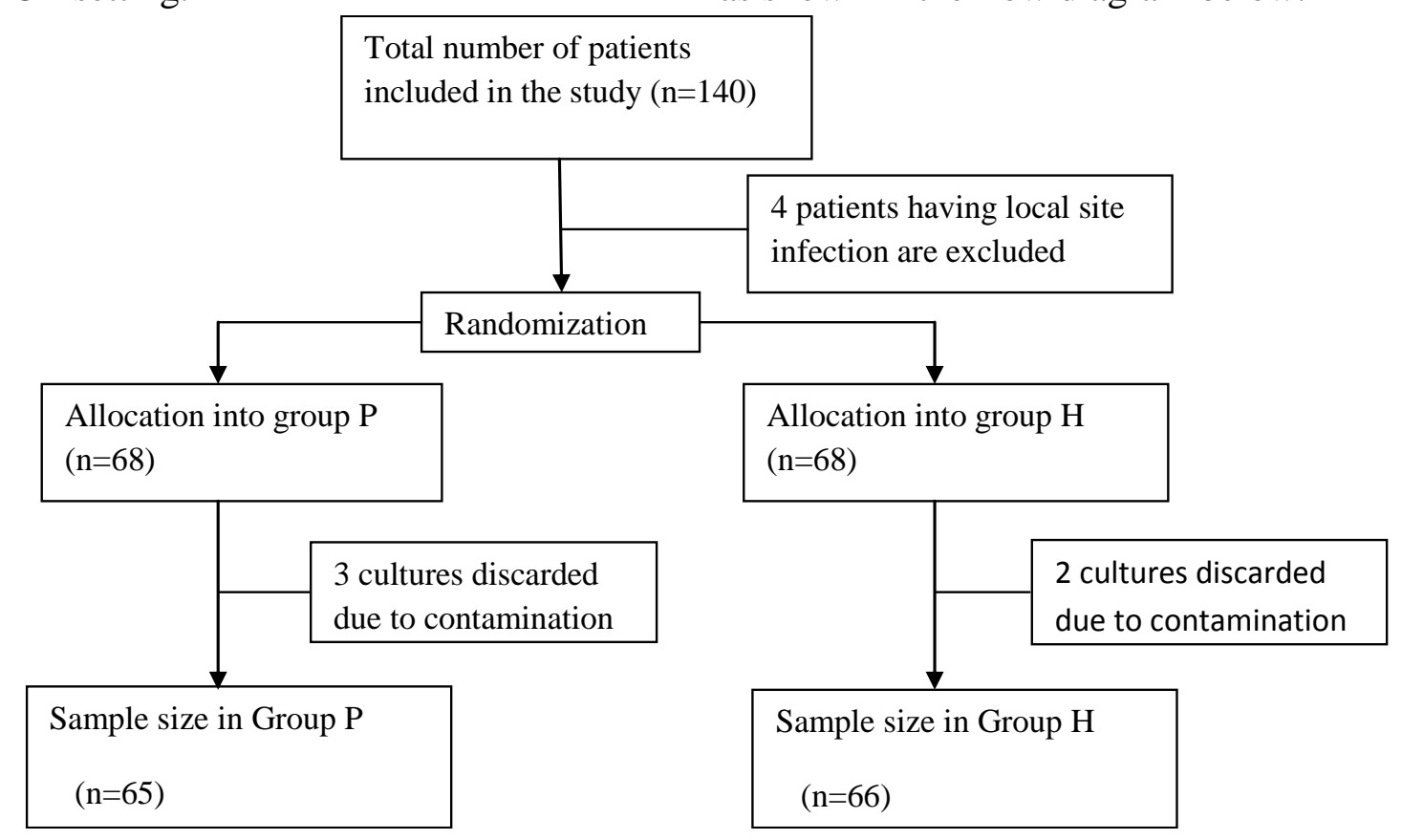

The first sample was taken using sterile swab sticks from 1 square inch area near the site of spinal anaesthesia before the application of studyantiseptic solution. The second sample was taken with sterile swab from same area from center to periphery in a circular fashion after skin preparation. A contact time of 3 minutes in group $\mathrm{P}$ and $30 \mathrm{sec}$ in group $\mathrm{H}$ was allowed after skin preparation. The swabs were sealed inside the labelled test tubes and sent to dept of microbiology for culture. Swabs were inoculated on sterile agar plates and incubated for 48 hours at $37^{\circ} \mathrm{C}$. A colony count was done at the end of 48 hours and results were documented. The microbiologist conducting the culture of the specimen was unaware of the study antiseptic solution. 


\section{Results}

The base line characteristics are comparable in this study as shown in the table 1 .

Table 1.Demographic profiles of both group

\begin{tabular}{|l|c|c|c|c|c|}
\hline $\begin{array}{l}\text { Group } \\
\text { Characteristics }\end{array}$ & Male : female & $\begin{array}{c}\text { Mean of } \\
\text { Age }\end{array}$ & $\begin{array}{c}\text { S.D of } \\
\text { Age }\end{array}$ & $\begin{array}{c}\text { Mean of } \\
\text { Height }\end{array}$ & $\begin{array}{c}\text { S.D of } \\
\text { Height }\end{array}$ \\
\hline Group-P & $34: 31$ & 34.18 & 10.06 & 63.21 & 3.049 \\
\hline Group-H & $37: 29$ & 35.00 & 8.733 & 63.54 & 2.851 \\
\hline P-value & & 0.656 & & 0.778 & \\
\hline
\end{tabular}

The mean age \& height of Group P \& Group H are shown in figure 1.

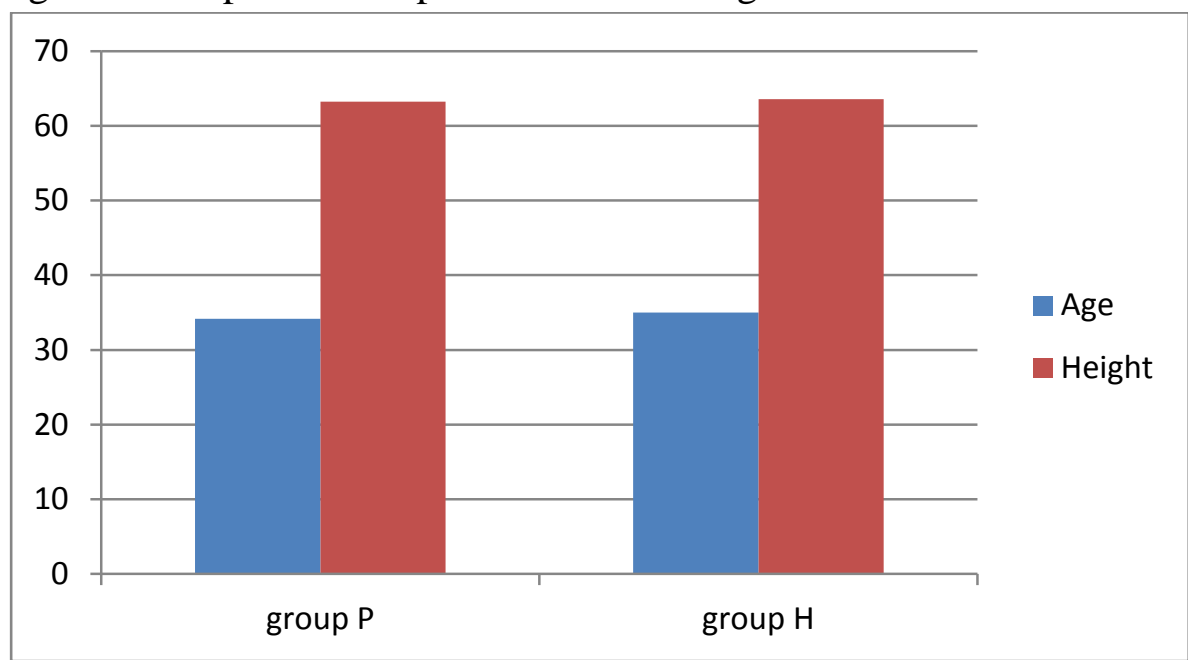

Figure 1

In this study, the skin swabs taken before application of antiseptics showed growth of skin commensals and some of other organisms like
Staph aureus, Staph epidermidis, Streptococcus,

Diptheroids as shown in the table $2 \&$ Figure 2.

Table 2 Skin commensals of both groups before application of antiseptics

\begin{tabular}{|l|c|c|c|c|}
\multicolumn{2}{c}{ Group P } & \multicolumn{2}{c|}{ Group H } \\
\hline Micro organisms & Number & Percentage & Number & Percentage \\
\hline Staph aureus & 37 & 56.9 & 41 & 62.1 \\
\hline Staph epidemidis & 31 & 47.6 & 28 & 42.4 \\
\hline Streptococcous & 21 & 32.3 & 18 & 27.3 \\
\hline Diptheroids & 8 & 12.3 & 11 & 16.6 \\
\hline Total & 65 & 100 & 66 & 100 \\
\hline
\end{tabular}

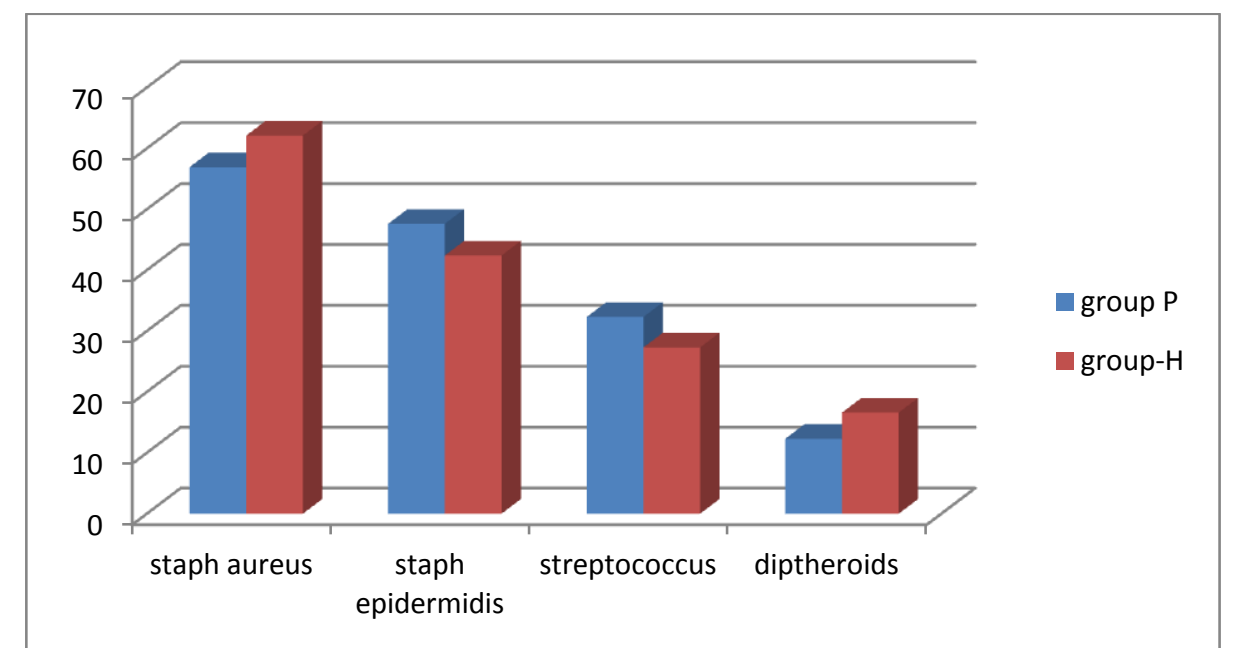

Figure 2 Skin commensals of both groups 
After $48 \mathrm{hr}$ incubation, number of growth of bacterial flora that was found in either of the groups are shown table 3 \& Figure 3.

Table 3 growth of bacterial flora after application of antiseptics

\begin{tabular}{|l|c|c|}
\hline Culture growth & Group P & Group H \\
\hline Positive cultures & $4(6.2 \%)$ & $3(4.6 \%)$ \\
\hline Negative cultures & $61(93.8 \%)$ & $63(95.4 \%)$ \\
\hline Total & $65(100 \%)$ & $66(100 \%)$ \\
\hline
\end{tabular}

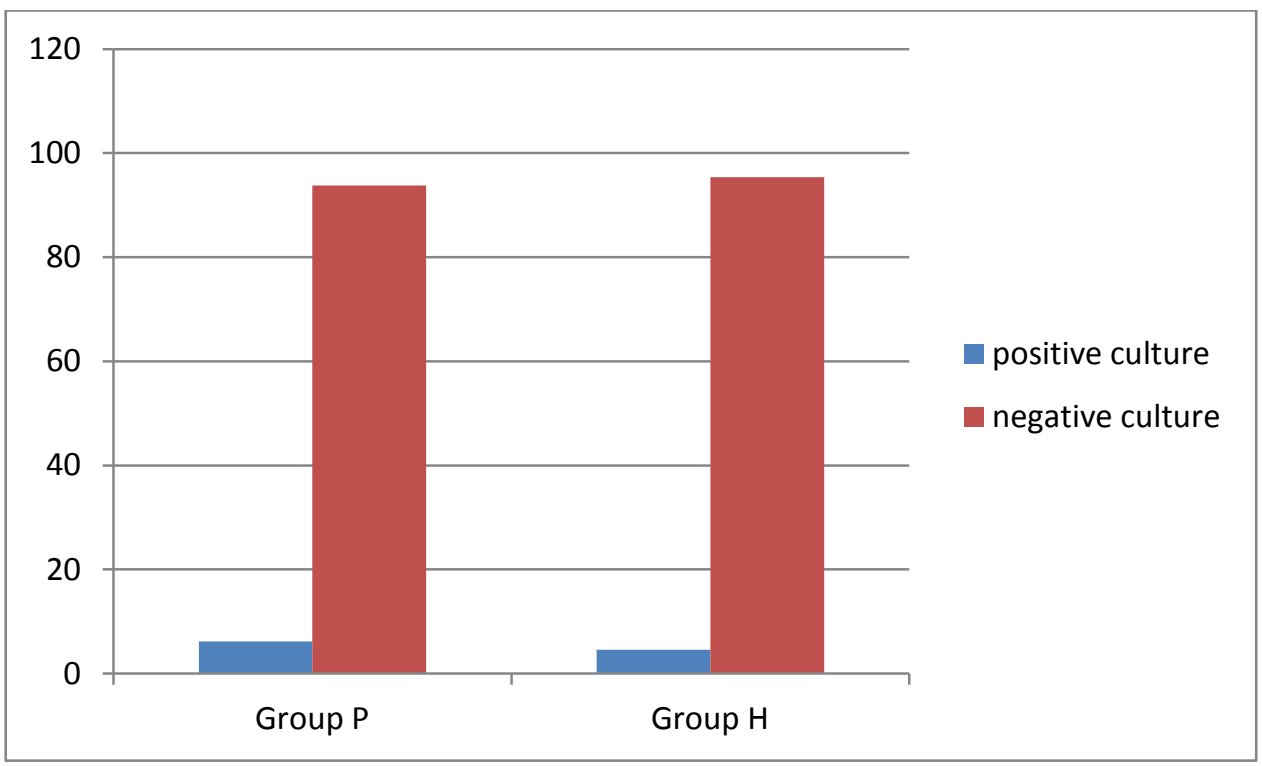

Figure 3 growth of bacterial flora after application of antiseptics

In this study, test statistic is chi square distribution with 1 degrees of freedom at $5 \%$ level of significance, for two tailed test the critical value is 3.841 which is much higher than the computed value. Therefore, we cannot reject the null hypothesis at $5 \%$ level of significance.

\section{Discussion}

Povidone iodine is the most commonly used skin antiseptic for years. Povidone-iodine exerts its antiseptic properties in two ways, first it substitutes the covalently bound hydrogen groups such as ${ }^{-} \mathrm{OH},-\mathrm{NH},-\mathrm{SH}$, or $-\mathrm{CH}$ groups. Second, povidone is an iodophor and it reacts with the oxygen containing functional groups. Free iodine determines the bactericidal activity; total iodine determines the ability to kill bacteria. Iodine solutions have rapid, broad-spectrum antimicrobial activity against bacteria, viruses, and fungi. It quickly penetrates micro-organisms and attacks neucleotides, fatty acids and thiol groups. It inhibits protein synthesis by oxidizing the thiol group. ${ }^{[4]}$ But it has the drawback that it has longer contact period of about 2-3 minutesand some studies showed that it may cause chemical meningitis on intrathecal injection?. This longer duration of contact period may not be beneficial in case of orthopedic surgeries like hip fracture, fracture neck of femur ,femur fracture etc in which there is difficulty in patient positioning and also it is painful for the patient to remain in that position for long time. Hygenium on the other hand takes lesser contact time and is equally effective .So it can be used in those patients safely. It can also be used as skin antiseptics before intravenous cannulation, intramuscular injection and central neuraxial blockade. Hygenium contains 2-propanolol,1-propanolol and macetronium ethyl sulphate as ingradients. The new CDC guideline on hand hygiene has indicated that the efficacy of alcohols is superior to many other active agents such as chlorhexidine gluconate or povidone iodine, also on the resident hand flora ${ }^{[12]}$. Alcohols without the addition of non-volatile agents such as quaternary ammonium 
compounds or chlorohexidine gluconate are regarded to have no sustained efficacy ${ }^{[12]}$. Alcohol-based hand rubs have been shown to have a better antimicrobial efficacy on both the transient and resident hand flora ${ }^{[11,13]}$. It has been shown earlier that ethanol at a concentration of $60 \%$ is far less effective against the resident hand flora than ethanol at $80 \%$ or more ${ }^{[14,15]}$. Kulkarni A et al observed no differences between $2 \%$ chlorhexidine and $10 \%$ povidone-iodine for skin disinfection in regard to costs, efficacy or sideeffects $^{[8]}$. Kareem SAMA et al observed alcoholbased hand rub significantly reduces the bacterial colony counts compared with standard surgical scrub? ${ }^{[7]}$. Most patients' swabs led to bacterial growth before but not after application of either antiseptic solution, indicating equal efficacy. Limitations of our study that we have not taken anaerobic microorganism culture into consideration.

\section{Conclusion:}

Povidone iodine and Hygenium are equally effective as antiseptic. Both the antiseptics spare spores. Both can be used as an alternative to each other. Hygenium can preferably used in situations where lesser time is required for preparation of skin prior to administration of cental neuraxial block and when patient positioning is difficult.

\section{References}

1. Royal College of Anaesthetists. Major complications of central neuraxial block in the United Kingdom. Report and findings of the 3rd National Audit Project of the Royal College of Anaesthetists, 2009. http://www.rcoa.ac.uk/node/4207 (accessed 06/10/13).

2. Horlocker TT, Birnbach DJ, Connis RT, et al. Practice advisory for the prevention, diagnosis, and management of infectious complications associated with neuraxial techniques. A report by the American Society of Anesthesiologists Task Force on infectious complications associated with neuraxial techniques. Anesthesiology 2010; 112: 530-45.

3. Hebl JR. The importance and implications of aseptic techniques during regional anesthesia.Regional Anesthesia and Pain Medicine 2006; 31: 311-23.

4. Fleischer W, Reimer K. Povidone-iodine in antisepsis - State of the art. Dermatology 1997;195:3-9.

5. Kadam R, Sharma C, Chhallani A, Yadav S. A comparative study between the efficacies of betadine scrub $(10 \%)$ versus alcohol based hand rub in preoperative hand disinfection. Int $\mathrm{J}$ Res Med Sci 2016;4:5141-3.

6. Sato S, Sakuragi T, Dan K. Human skin flora as a potential source of epidural abscess. Anesthesiology 1996; 85:1276-82.

7. Kareem SAMA, Mahmood AA, Husein ZR. Ibn Al-Haithem Teaching Eye Hospital, Baghdad, Iraq. Alcohol Based Handrub versus Traditional Hand Scrub as Surgical hand Disinfection in a Tertiary Eye Teaching Hospital. J ClinEsp Ophthalmology. 2014;5(3): doi:10.4172/2155-9570.1000340.

8. Kulkarni AP, Awode RM. A prospective randomised trial to compare the efficacy of povidone-iodine $10 \%$ and chlorhexidine $2 \%$ for skin disinfection.Indian J Anaesth. 2013;57(3):270-5.

9. Bradbury CL, Hale B, Mather I, Suri I. Skin disinfection before spinal anaesthesia for caesarean section: a survey of UK practice. International Journal of Obstetric Anesthesia 2011; 20; 101-2.

10. Checketts MR. Wash and go - but with what?Skin antiseptic solutions for central neuraxial block.Anaesthesia2012; 67: 81922.

11. Rotter ML: Arguments for the alcoholic hand disinfection. Journal of Hospital Infection 2001, 48:S4-S8.

12. Boyce JM, Pittet D: Guideline for hand hygiene in health-care settings. 
Recommendations of the healthcare infection control practices advisory committee and the HICPAC/SHEA/APIC/IDSA hand hygiene task force. MMWR - Morbidity \& Mortality Weekly Report 2002, 51:1-45.

13. Kampf G, Kramer A: Epidemiologic background of hand hygiene and evaluation of the most important agents for scrubs and rubs. Clinical Microbiology Reviews 2004, 17:863-893.

14. Rotter ML: Hand washing and hand disinfection. In Hospital epidemiology and infection control 2nd edition.Edited by: Mayhall CG. Philadelphia, Lippincott Williams \& Wilkins; 1999:1339-1355.

15. Kampf G, Kapella M: Suitability of Sterillium Gel for surgical hand disinfection. Journal of Hospital Infection 2003, 54:222-225. 